\title{
What does an intern doctor actually do? A quantification of time on work
}

\section{activities}

\author{
James Jia Jun Chen, Vinh Ngo, Chang Mien Chew, Malcolm Keng Yee Teo, Rene Zellweger
}

Royal Perth Hospital, Australia

\section{RESEARCH}

Please cite this paper as: Chen JJJ, Ngo V, Chew CM, Teo MKY, Zellweger R. What does an intern doctor actually do? A quantification of time on work activities. AMJ 2017;10(12):1008-1013.

https://doi.org/10.21767/AMJ.2017.3226

\section{Corresponding Author:}

Rene Zellweger

Professor, Royal Perth Hospital, Perth, Australia

Email: rene.zellweger@health.wa.gov.au

\section{ABSTRACT}

\section{Background}

Interns, or first year junior doctors, have traditionally been used as an adaptable frontline solution to many of the changes in healthcare, utilising their broad skill sets for both direct patient care and administrative burdens. While there are studies that focus on the total hours junior doctors work, there are few that analyse the specific tasks they do and how they dedicate their work time.

\section{Aims}

We aim to quantify the amount of time intern doctors spent on specific tasks during a shift.

\section{Methods}

This is a multi-centred, retrospective, self-reported study that was carried out in a public tertiary hospital network in Western Australia, comprising one tertiary, two metropolitan, and three regional hospitals. 68 individual shifts were reported, accounting for 605.72 hours. Participants reported time spent, in fifteen minute segments, on categories grossly defined as clerical tasks, clinical tasks, teaching, and personal time. Participants were also asked about their satisfaction with the amount of clinical exposure during the reported shift.
Results

Direct patient care accounted for 22 per cent of total shift time, indirect care 74 per cent, and personal time 4 per cent. Discharge summaries accounted for the most timeper-shift at 26 per cent, followed by medical note documentation at 14 per cent, with the least being teaching at 2 per cent. Direct patient contact by interns during a shift was on average 12 per cent (SD 14 per cent). 12 interns or 18 per cent of all responses reported no direct patient contact ( 0 per cent) during a shift. Interns working in emergency medicine spent 44 per cent of their shift on direct patient contact, significantly more compared to their medicine and surgical colleagues.

\section{Conclusion}

Indirect care activities consume almost three times as much time as direct care activities. Interns are mostly unsatisfied with their amount of clinical exposure per shift. The results concur with the current literature of increasing levels of clerical and administrative burden, and decreasing relevant clinical exposure in doctors' work.

\section{Key Words}

Intern time study, junior doctors, work hours, clerical tasks, clinical tasks

\section{What this study adds:}

\section{What is known about this subject?}

Changes in administrative burdens faced by doctors have led to increasing rates of job dissatisfaction, mental health issues, and burnout.

\section{What new information is offered in this study?}

Direct patient care (that involving interacting with a patient) accounted for 22.53 per cent of surveyed time, indirect care 73.83 per cent, and personal time 3.64 per cent. 12 respondents reported no direct patient contact ( 0 per cent) during a shift. 
3. What are the implications for research, policy, or practice?

It is concerning that the proportion of time junior doctors spend on direct patient care is low. There needs to be a reprioritisation of professional development at the core of an intern's job otherwise the very future of the medical profession, and more importantly, the welfare of our patients, may be at stake.

\section{Background}

Healthcare has undergone drastic transformations in recent years and the demands on junior doctors has followed suit. Some of these changes in the healthcare landscape include technological innovation, distribution of tasks amongst increasingly specialised fields, and increased emphasis on documentation. ${ }^{1}$ This is in the context of tightening fiscal conditions and rising needs for healthcare. As junior doctors' work hours have decreased and demands for documentation and administrative tasks increased, there is a growing concern that time available for direct patient care and teaching has diminished. This has led to less professional development of junior doctors, but also job dissatisfaction, mental health issues, and burnout. Shanafelt et al. ${ }^{2,3}$ Reported a 12 per cent increase in doctors who reported some signs of burnout from 2011-2014 during the introduction of electronic health records. Furthermore, excessive paperwork has also been identified as a major cause of work-related stress. ${ }^{4}$ All these pressures take their toll, and may have contributed to a recent string of junior doctor suicides, including the unfortunate deaths of Dr. Abbott and Dr. Moutzouris. ${ }^{5}$ despite future doctors beginning medical school with a better mental health profile that those pursuing other fields. ${ }^{6}$

Interns, or first year junior doctors, have traditionally been used as an adaptable frontline solution to many of the changes in healthcare, utilising their broad skill sets for both direct patient care and administrative burdens. While there are studies that focus on the total hours junior doctors work, there are few that analyse the specific tasks they do and how they dedicate their work time in this new context. Existing studies in the area have often been time motion studies with small sample sizes and not truly representative of a cohort of junior doctors.

We conducted a multi-centred, self-reported study of intern work activity to quantify the time spent on specific activities during a shift. Understanding the breakdown of intern work is important as it identifies current inefficiencies that may be improved upon while providing a baseline for future interventions.

\section{Method}

\section{Setting}

The study was undertaken at a public tertiary teaching hospital network in Western Australia during the penultimate and final internship rotations from August to December 2016. This network comprises 1097 beds throughout one tertiary referral centre, two metropolitan hospitals and three general regional hospitals; all of which are considered teaching hospitals. These hospitals have paper based medical records that encompasses medical documentation, admission paperwork, nursing observations, nursing and allied health care plans, and inpatient medication orders. An electronic system was utilised for discharge summaries, discharge medications and referrals. Ordering of pathology requests and viewing of investigation results was done electronically. However, radiology requests required delivery in person to the radiology department in most instances.

\section{Sample and data collection}

All interns across the network $(n=83)$ were invited to partake in this multi-centered, retrospective self-reported study. Rotations were categorised by specialty area into medical (including psychiatry), surgical, and emergency medicine. Interns were asked to report on up to two shifts through an online survey. The survey included demographic information (hospital, rotation, shift-length, date of the shift) and a breakdown of activities, as defined below, during a shift. At the end of their shift, participants retrospectively reported the duration spent on each activity, with a validation tool, ensuring the whole shift was accounted for. The order of shift activities presented in the survey was randomised to reduce bias. Participants were also asked a question regarding the level of satisfaction of clinical exposure in their role during the shift.

\section{Categories}

We categorized intern work activities based on recommendations of a systematic review of time studies evaluating physicians' activities. ${ }^{7}$ The categories were adapted to local factors and simplified to increase participation rates, but to also work within the constraints of the study. The categories were: professional communication, direct patient care, procedure and theatre, teaching, discharge summaries, medical note documentation, clerical matters, and personal time. Definitions for each category can be found in Table 1 . In evaluating the data, these categories were grouped into direct patient care, indirect patient care, and personal time. 


\section{Analysis}

To account for different shift durations, the time spent on each activity was converted into a percentage of the total shift duration. Statistical analysis was performed using descriptive statistics that identified the proportion of time dedicated to each category. To compare the times spent on each category, a one-way ANOVA analysis was performed. When a statistically significant difference was found, a posthoc analysis THS with Bonferroni correction was carried out to identify the source of the difference. Analysis was performed on ' $R$ ' and 'Microsoft Excel' software.

\section{Results}

Sixty eight responses were received, reporting a total of 605.72 worked hours. The majority of interns sampled were from the tertiary hospital $(n=50)$, then regional hospitals $(n=12)$ and finally peripheral hospitals $(n=6) .36$ respondents were on surgical rotations, 24 on medical, and 8 on emergency medicine. The average shift duration was 9.08 hours (545 minutes).

Table 2 displays the average percentage of time interns dedicated per shift to a particular activity and the associated standard deviation. Direct patient care accounted for 22.53 per cent, indirect care 73.83 per cent and personal time 3.64 per cent (Figure 1). Discharge summaries accounted for the most time-per-shift at 26 per cent. The lowest proportion of time was for teaching at 2.39 per cent. Direct patient contact by interns was on average 12.75 per cent of all time (SD 14 per cent), being the highest of all the categories. 12 respondents reported no direct patient contact ( 0 per cent) during a shift.

Interns working in emergency medicine on average spent significantly more time on direct patient contact (44.59 per cent) and less time on discharge summaries (8.15 per cent) as compared to interns working in medicine and surgery (ANOVA data). Surgical interns spent significantly more time on radiology tasks compared to medical interns (6.24 per cent vs. 3.31 per cent), however, they also spent more time on procedures (9.5 per cent vs. 3.46 per cent).

A majority of interns (37/68) were not satisfied with the amount of clinical exposure they received.

\section{Discussion}

Our study aimed to provide an understanding of junior doctor activity across a multi-centre hospital network to capture overarching trends. Activities that contribute to junior doctor professional development accounted for only 22 per cent of the time recorded. More concerningly, 12 interns (17 per cent of respondents) reported no such activity. We can see why a majority of interns were not satisfied with their clinical exposure. This is compounded by low levels of teaching in any form at teaching hospitals (2.39 per cent). Given that the priority of the junior doctor is to develop professionally through relevant clinical exposure, this is a sobering finding.

Sixty-two per cent of the interns' time was dedicated to indirect tasks, with much of this accounted for by discharge summaries (26 per cent). This is in line with studies by Tipping et al. ${ }^{7}$ and Kim et al. ${ }^{8}$ which showed that a large majority of junior doctors' time was spent on indirect patient care. The time taken to complete discharge summaries is significantly greater in our study compared to others which suggest proportions of closer to 10 percent. $^{9}$ This may potentially be accounted for by an electronic discharge summary application that was newly implemented in the surveyed network of hospitals that has had significant performance issues. With no other obvious explanation that we could identify, this significant difference in time taken to complete discharge summaries highlights the importance of thorough consideration when introducing new technology in healthcare.

Interns who worked in emergency specialties enjoyed the highest level of direct patient contact (44 per cent) and procedures (9 per cent) while having the lowest proportion of time attributed to discharge summaries ( 8 per cent) and clerical matters ( 4 per cent). This is in line with the nature of the specialty, with higher levels of autonomy and lower administrative burdens. ${ }^{10}$

Thirty seven of 68 interns (54 per cent) were dissatisfied with the clinical exposure that they received. Given that only 20.14 per cent of an intern's activities were accounted for by direct patient contact, the investigators expected the dissatisfaction to be even greater. It is possible that a longstanding culture of interns being 'paper pushers' has set the precedent such that new interns are not dissatisfied with having less clinical exposure. This may be the start of deeper problems for the future of medicine in which doctors are less dedicated to clinical work - including seeing their patients, seizing learning opportunities, and doing research - to carry out more administration. Unfortunately, our data collection method did not allow any further analysis to establish a causal link.

The focus of interns is not only to play a role in facilitating patient care but to also develop themselves professionally through relevant teaching and clinical experience, with the 
aim of working towards specialty training. ${ }^{11}$ There should be an expectation of nurturing interns to ensure that they can develop as much as possible in a supportive environment. This study suggests that the burden of administrative and documentation tasks is compromising the amount of time that interns can dedicate to seeking clinical exposure. Furthermore, interns often feel a greater sense of priority to satisfy their administrative burden much more than to contribute to their professional development, a result of expectations within the medical hierarchy. This has been worsened by financial constraints forcing stricter working hours, with administration actively discouraging overtime across the junior workforce. This culture disincentives the training of junior doctors, including those who wish to spend extra time in the hospital to gain more clinical exposure. More concerning is that these findings were similar across the different hospitals in the surveyed network, suggesting a more systemic issue than a local one. Furthermore, other prevocational junior doctors have similar job profiles and therefore these findings are likely to apply to them.

There are limitations to the study's findings, notably the retrospective self-reporting. This is likely to have resulted in non-adherence to category definitions and underreporting of certain areas such as personal activity. This is in comparison to the findings of other studies which utilized labour intensive data collection methods. ${ }^{9}$ Due to the nature of multidisciplinary care, doctors are often distracted from achieving single tasks and subsequently multi-tasking; we did not account for this, assuming that each unit of time was dedicated to only one task. The study was cross sectional in nature and a longitudinal study may be considered in the future to more accurately capture activity distribution. We tolerated these limitations to create a study with a large scope and to increase participation rates by interns. Given this was a retrospective study, the sample size of 83 is low and therefore the confidence interval is also low. We would recommend a continuation of this study, with the above weaknesses addressed, to increase the sample size and confidence interval to draw further conclusions from this research.

\section{Conclusion}

Our findings are consistent with the current literature related to this area and confirm the anecdotal perception that there is an increasing administrative burden on interns. Overall, this study captures the nature of work for interns and the relevant trends. Despite the centrality of patient care to intern training, it is concerning that the proportion of time they spend on this is low. As the most junior medical staff, interns have borne a significant detrimental burden of the changes and expectations to healthcare. There needs to be a re-prioritisation of professional development at the core of an intern's job and efforts made to help assist that. Considerations include decreased administrative and documentation burdens where possible. Otherwise, the very future of the medical profession, and more importantly, the welfare of our patients, may be at stake.

\section{References}

1. Friedberg MW, Chen PG, Van Busum KR, et al. Factors affecting physician professional satisfaction and their implications for patient care, health systems, and health policy. Rand Health Q. 2014;3(4):1.

2. Shanafelt TD, Hasan $O$, Dyrbye $L N$, et al. Changes in burnout and satisfaction with work-life balance in physicians and the general US working population between 2011 and 2014. Mayo Clin Proc. 2015;90(12):1600-1613.

3. Shanafelt TD, Boone S, Tan L, et al. Burnout and satisfaction with work-life balance among US physicians relative to the general US population. Arch Intern Med. 2012;172(18):1377-1385.

4. Lewington K. Cohort study of 2006 medical graduates Ninth report. BMA; 2015.

5. Brennan R. Junior doctor suicides: at least 20 lives lost due to enornmous pressure. The Daily Telegraph; 2017. [updated Mar 17; cited 2017 Sep 17]. Available from: http://www.dailytelegraph.com.au/news/nsw/juniordoctor-suicides-at-least-20-lives-lost-due-to-enormouspressure/newsstory/62606951f02d37f6365f6f00e4f492c2

6. Brazeau CM, Shanafelt T, Durning SJ, et al. Distress among matriculating medical students relative to the general population. Acad Med. 2014;89(11):1520-1525.

7. Tipping MD, Forth VE, O'leary KJ, et al. Where did the day go? -A time-motion study of hospitalists. J Hosp Med. 2010;5(6):323-328.

8. Kim CS, Lovejoy W, Paulsen M, et al. Hospitalist time usage and cyclicality: opportunities to improve efficiency. J Hosp Med. 2010;5(6):329-334.

9. Westbrook JI, Ampt A, Kearney L, et al. All in a day's work: an observational study to quantify how and with whom doctors on hospital wards spend their time. The Med J Aust. 2008;188(9):506-509.

10. Chisholm CD, Weaver CS, Whenmouth L, et al. A task analysis of emergency physician activities in academic and community settings. Ann Emerg Med. 2011;58(2):117-122.

11. Rolfe I, Gordon J, Atherton S, et al. A system for maintaining the educational and training standards of 
junior doctors. Med Educ. 1998;32:426-431.

\section{ACKNOWLEDGEMENTS}

We thank Professor Zellweger for his oversight of this work, and all the participants for their time and cooperation.

\section{PEER REVIEW}

Not commissioned. Externally peer reviewed.

\section{CONFLICTS OF INTEREST}

The authors declare that they have no competing interests.

\section{FUNDING}

None

\section{ETHICS COMMITTEE APPROVAL}

Ethics has been approved by the relevant body, GEKO (Quality Activity 14016).

Figure 1: Distribution of activities performed by interns as a percentage of total shift duration

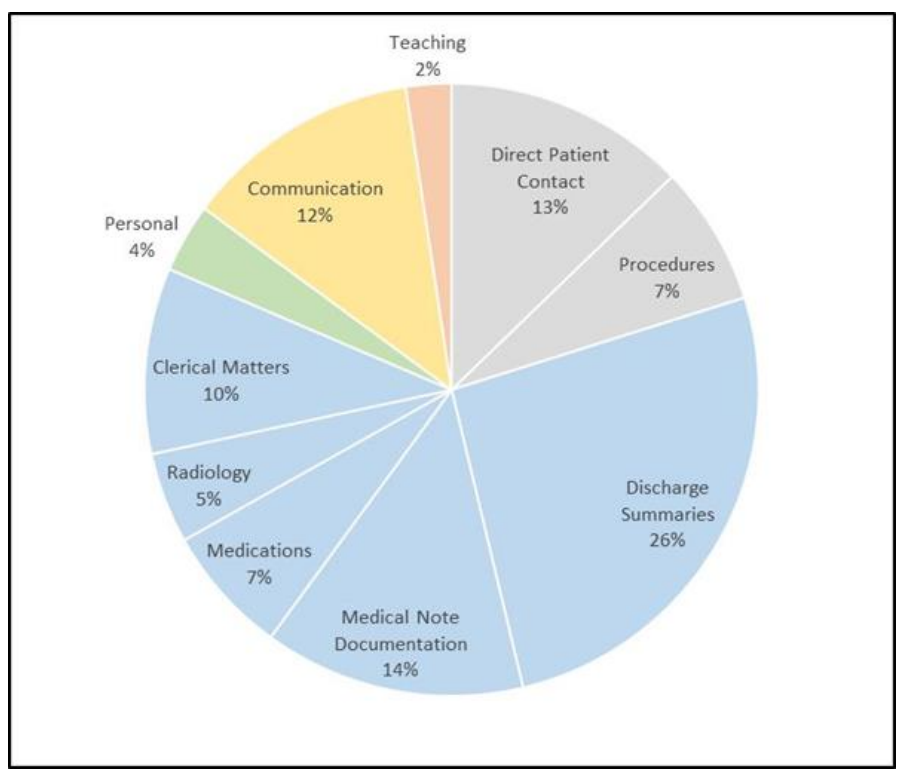


Table 1: Definition of categories used within our study

\begin{tabular}{|c|c|c|}
\hline Category & \multicolumn{2}{|l|}{ Definition } \\
\hline \multirow{3}{*}{$\begin{array}{l}\text { Direct patient care } \\
\text { Tasks relating to } \\
\text { patient care and } \\
\text { involving patient } \\
\text { contact }\end{array}$} & \multirow{2}{*}{ Direct patient contact } & $\begin{array}{l}\text { History, examination, and communication with patient and/or } \\
\text { family. }\end{array}$ \\
\hline & & $\begin{array}{l}\text { Excludes diagnostic or therapeutic procedures performed by the } \\
\text { intern (see 'Procedures and Theatre'). }\end{array}$ \\
\hline & $\begin{array}{l}\text { Procedures and theatre } \\
\text { experience }\end{array}$ & $\begin{array}{l}\text { Therapeutic and diagnostic procedures performed by the intern as } \\
\text { well as time spent in theatre assisting or observing. }\end{array}$ \\
\hline \multirow{6}{*}{$\begin{array}{l}\text { Indirect patient } \\
\text { care } \\
\text { Tasks relating to } \\
\text { patient care but } \\
\text { not involving } \\
\text { patient contact }\end{array}$} & Discharge summaries & Writing of discharge summaries. \\
\hline & \multirow{2}{*}{$\begin{array}{l}\text { Medical note } \\
\text { Documentation }\end{array}$} & Any record of patient information on paper or electronically. \\
\hline & & $\begin{array}{l}\text { Excludes medication documentation, discharge summaries and } \\
\text { radiology requests (see relevant sections). }\end{array}$ \\
\hline & Radiology & $\begin{array}{l}\text { Writing and requesting radiology imaging including subsequent } \\
\text { discussion with radiologists (for approval) and other service } \\
\text { providers (e.g. echocardiogram, ultrasound). }\end{array}$ \\
\hline & Medications & $\begin{array}{l}\text { All tasks associated with medications including intravenous fluids. } \\
\text { Includes preparation, administration, documentation, and } \\
\text { discussion with peers. Includes activities related to the provision of } \\
\text { discharge medications. }\end{array}$ \\
\hline & Clerical Matters & $\begin{array}{l}\text { Administrative activities not explicitly described above and not } \\
\text { related to direct and indirect patient care. Includes: } \\
\text { - Organisation of patient related appointments; } \\
\text { - Documentation for coding/legal/finance reasons; } \\
\text { - Transportation related documentation for patients; } \\
\text { - Patient certificates (e.g. sick notes, workers compensation); } \\
\text { - Patient orientated applications (e.g. rehabilitation, funding). }\end{array}$ \\
\hline Teaching & \multicolumn{2}{|c|}{ Teaching or education provided to the intern in either a formal or informal setting. } \\
\hline \multirow[t]{2}{*}{$\begin{array}{l}\text { Professional } \\
\text { communication }\end{array}$} & \multicolumn{2}{|c|}{$\begin{array}{l}\text { Communications in all forms with another doctor or health professional, including handovers, } \\
\text { team meetings, and requesting medical consultations. }\end{array}$} \\
\hline & \multicolumn{2}{|c|}{ Excludes discussion with radiologist regarding imaging requests (see 'Radiology'). } \\
\hline Personal time & \multicolumn{2}{|c|}{ All non-work activities such as walking, breaks, meals, and personal phone calls. } \\
\hline
\end{tabular}

Table 2: Distribution of activities of interns as a percentage of total shift duration

\begin{tabular}{|l|l|}
\hline Tasks & Average time (\%) of shift \pm SD \\
\hline Discharge Summaries & $26.12 \pm 12.63 \%$ \\
\hline Medical note documentation & $13.77 \pm 7.49 \%$ \\
\hline Direct patient contact & $12.75 \pm 14.38 \%$ \\
\hline Professional Communication & $12.52 \pm 6.03 \%$ \\
\hline Clerical Matters & $9.82 \pm 5.68 \%$ \\
\hline Medications & $6.80 \pm 4.64 \%$ \\
\hline Procedures & $5.09 \pm 4.23 \%$ \\
\hline Radiology & $4.80 \pm 3.96 \%$ \\
\hline Personal & $3.64 \pm 2.71 \%$ \\
\hline Teaching & $2.39 \pm 4.31 \%$ \\
\hline Theatre & $2.30 \pm 5.73 \%$ \\
\hline
\end{tabular}

